\title{
ПРИМЕНЕНИЕ ИНТЕРАКТИВНЫХ ЛОГОПЕДИЧЕСКИХ ТРЕНАЖЕРОВ В КОРРЕКЦИИ ЗВУКОПРОИЗНОШЕНИЯ ДОШКОЛЬНИКОВ С ОБЩИМ НЕДОРАЗВИТИЕМ РЕЧИ'
}

\section{THE APPLICATION OF INTERACTIVE LOGOPEDIC SIMULATORS IN CORRECTION OF SOUND PRODUCTION OF PRESCHOOLERS WITH GENERAL SPEECH UNDER DEVELOPMENT}

N. Minaeva

A. Ledakova

Summary: The article is devoted to the problem of improving correctional work on sound pronunciation in children with general speech underdevelopment (GSD) of preschool age. The authors considered the possibilities of using interactive speech therapy simulators as a means to increase the efficiency of speech therapy work in this direction. The article presents the results of an experimental study aimed at the development and testing of a set of speech therapy simulators for correcting the sound pronunciation of preschoolers with GSD.

Keywords: interactive simulator, preschoolers with general speech underdevelopment, sound pronunciation, speech therapy classes.
Минаева Наталья Геннадьевна

К.п.н., дочент, ФГБОУ ВО «Мордовский государственный педагогический университет имени М.Е. Евсевьева»

(2. Саранск) natmi27@yandex.ru

Ледакова Анна Владимировна

ФГБОУ ВО «Мордовский государственный педагогический университет имени М.Е. Евсевьева» (2. Саранск)

led1421@yandex.ru

Аннотация: (татья посвящена проблеме совершенствования коррекционной работы по звукопроизношения у детей с общим недоразвитием речи (ОНР) дошкольного возраста. Авторами рассмотрены возможности применения интерактивных логопедических тренажеров как средства, позволяющего повысить эффективность логопедической работы в данном направлении. В статье представлены результаты опытно-экспериментального исследования, направленного разработку и апробацию комплекса логопедических тренажеров для коррекции звукопроизношения дошкольников с ОНР.

Ключевые слова: интерактивный тренажер, дошкольники с общим недоразвитием речи, звукопроизношение, логопедические занятия.

В логопедической практике все более востребованными сегодня становятся логопедические тренажеры. Интерактивные тренажеры представляют собой современное и оригинальное средство, позволяющее совместить функции обучения, закрепления, контроля, оценки и самооценки обучающихся [2]. Специфика тренажера проявляется в том, что работа с ним реализуется в рамках обратной связи, предполагающей разбор допущенных ошибок, комментарии к неверным ответам, организация ветвлений по ответам и т.п., и позволяющей обучающимся вернуться к воспроизведению недостаточно успешно освоенного материала [5].

По мнению 3.А. Репиной, Л.Р. Лизуновой, координированная работа моторного, слухового и зрительного анализаторов при выполнении компьютерных заданий позволяет активизировать компенсаторные механизмы организма дошкольника [7]. ствует повышению ее эффективности [6].

Исследование выполнено в рамках гранта на проведение научно-исследовательских работ по приоритетным направ лениям научной деятельности вузов-партнеров по сетевому взаимодействию ФГБОУ ВО «Чувашский государственный педагогический университет им. И. Я. Яковлева» по теме «Научно-методические аспекты применения инновационных образовательных технологий в коррекционной работе с дошкольниками с ограниченными возможностями здоровья» 
С.В. Архипова, А.С. Чаприна отмечают, что во время взаимодействия ребенка с компьютерными программами сводится к минимуму проявление негативизма, вызванного многократным повторением одних и тех же операций, что обеспечивает благотворные условия для продуктивной работы [1].

Исследователи отмечают, что в коррекционно-образовательном процессе целесообразно применять компьютерные тренажеры, отвечающие следующим принципам: дифференцированного подхода к обучению (тренажер позволяет выбирать сложность и объем заданий в соответствии с индивидуальными возможностями ребенка); полисенсорного воздействия (задействует сохранные анализаторы); системного подхода (например, использование тренажера позволяет коррегировать нарушения звукопроизношения через развитие следующих компонентов: звукопроизносительные навыки, фонематический анализ и синтез, фонематические представления, артикуляционная моторика, просодических компонентов речи); доступности (предлагаемые дидактические задания должны соответствовать уровню речевого развития и возрасту дошкольника); объективности (результаты деятельности дошкольника выводятся на экране, поэтому субъективная оценка не имеет места быть); игровой стратегии (представленные задания решают задачи коррекции через игровую ситуацию); интерактивность (работа с тренажером предполагает обратную связь) [8].

В.М. Гордиевских определяет следующие требования, предъявляемые к развивающим и обучающим логопедическим тренажерам: интерактивный тренажер должен включать в себя указания к минимальным системным требованиям компьютера, кроме того, должна быть обозначена возрастная категория, на которую он нацелен; программе необходимо иметь звуковое оформление, насыщенный и привлекательный сюжет; объекты, вынесенные на экране, должны быть четкими, яркими и понятными детям; транслируемые инструкции представляются исключительно на русском языке; рекомендуется озвучивание текста заданий; периоды и эпизоды игры должны быть не более 3-5 минут; интерактивный тренажер должен способствовать всестороннему развитию детей, давать им знания, обучать навыкам в незатейливом игровом формате [3].

Организацию обучения дошкольников с применением компьютерных технологий рекомендуется осуществлять с соблюдением следующих условий: а) монитор должен быть размещен на уровне глаз ребенка на расстоянии 50 см; б) детям 5-6 лет на работу с компьютером можно выделяется по 10 минут, в 3 раза в неделю, с 6-7 лет разрешается увеличить время до 15 минут; в) через каждые 1,5-2 минуты необходимо переводить взгляд ребенка от монитора; г) во время работы за компьютером у ребенка должна быть ровная спина; д) по истечению сессии желательно сделать небольшую физкультурную минутку [4].

В рамках нашего исследования была организована опытно-экспериментальная работа, направленная на повышение эффективности логопедической работы по коррекции звукопроизносительной стороны речи дошкольников с ОНР. Ее целью стала разработка и апробация интерактивных логопедических тренажеров, позволяющих осуществлять коррекцию звукопроизношения у дошкольников с общим недоразвитием речи. В связи с этим в процессе эксперимента решались следующие задачи: подготовить интерактивные тренажеры, направленные на коррекцию звукопроизношения у дошкольников с общим недоразвитием речи; спроектировать основные этапы логопедического занятия с применением интерактивных тренажеров, апробировать серию занятий.

Эксперимент был проведен в ноябре и декабре 20192020 учебного года на базе МАДОУ «Центр развития ребенка - детский сад №17» г. о. Саранск. В нем приняли участие 12 детей 5-6 лет с логопедическим заключением о наличии ОНР II-III уровня.

В ходе исследования был разработан комплекс логопедических тренажеров, направленных на постановку, автоматизацию и дифференциацию следующих групп звуков: [c] - [ш], [р] - [л]. В процессе создания тренажеров мы опирались на методические разработки Т.Е. Филичевой, Г.В. Чиркиной, Е.Л. Черкасовой. Кроме того, нами разработаны и описаны все основные этапы логопедических занятий с применением данных интерактивных тренажеров с целью оптимизации коррекционной работы. Разработанные этапы логопедических занятий предполагают их частичное внедрение в традиционные конспекты коррекционных занятий.

Логопедические тренажеры, применявшиеся в ходе формирующего эксперимента, были созданы нами с помощью программы Microsoft Office PowerPoint, позволяющей динамично выстраивать видеоряд и звуковой фон, что облегчало процесс восприятия и запоминания информации, позволяла удерживать внимание дошкольников, создавала дополнительную мотивацию для последующих занятий, сокращала время коррекционной работы. Изучаемый материал, предъявляемый в ярком, интересном и доступном виде, вызывал у ребенка особый интерес. Привлекательный материал и динамичная форма его подачи, обыгрывание ситуации делало процесс изучения и закрепления материала более непринужденным, динамичным, но при этом и более целенаправленным, осознанным, долгосрочным и качественным. 
В комплекс вошли следующие тренажеры.

1. - логопедический тренажер «Тигренок и его друзья», направленный на поставку и автоматизацию звукопроизношения [р];

2. - логопедический тренажер «Лунтик. Полет на Луну», направленный на постановку и автоматизацию [л];

3. - логопедический тренажер «Фиксики в стране звуков», направленный на постановку и автоматизацию [c] - [ш];

4. - логопедический тренажер «Простоквашино», направленный на дифференциацию [c] - [ш];

5. - логопедический тренажер «Король Лев», направленный на дифференциацию [р] - [л].

Охарактеризуем их подробнее. Основные компоненты разработанных логопедических тренажеров:

1. Блок артикуляционной гимнастики, который включал в себя упражнения, направленные на подготовку артикуляционного аппарата к постановке и правильному произношению корригируемых звуков;

2. Блок дыхательной гимнастики, предусматривающий выполнение заданий, направленных на разминку и подготовку голосовых связок к выполнению речевых упражнений.

3. Основной блок упражнений, который представлял собой разнообразные типы упражнений, позволяющие отработать с ребенком проблемные звуки в различных его позициях, а именно: в открытых и закрытых слогах, в начале, середине и конце слова, а также в словосочетаниях и предложениях.

4. Оценочный блок, подразумевающий рефлексию проведенного занятия.

Инструкции каждого блока тренажеров транслировалась мультипликационными персонажами, которые не только давали задания, но и оценивали работу ребенка, тем самым мотивировали его к дальнейшей деятельности. Интерактивные тренажеры также содержали подсказки, существовала возможность повторного выполнения задания, повторения однотипной группы заданий. Логичный переход от одного блока тренажера к другому обуславливало наличие привлекательной сюжетной линии, которая в свою очередь позволяла создать целостную картину целого цикла занятий. Данные блоки были представлены в тренажерах как в полном объеме, так и в объеме, необходимом для решения поставленных задач.

Тренажеры применялись на различных этапах логопедического занятия.

1. Подготовка артикуляционного аппарата. На данном этапе могла осуществляться работа с блоком, включающем в себя артикуляционные упражне- ния, которые представлены в каждом разработанном тренажере и отличаются по своей структуре. Это позволяло разнообразить данный обязательный, постоянно повторяющийся этап.

2. Дыхательная гимнастика. Упражнения данного этапа были представлены в трех разных вариантах, каждый из которых мог быть использован на любом логопедическом занятии. Интерактивность разработанных упражнений позволяла удерживать внимание дошкольников и увеличивать продолжительность выдыхаемой воздушной струи.

3. Сообщение темы занятия. Данный этап нашел свое отражение в репликах героев мультипликационных проектов, представленных в интерактивных тренажерах.

4. Сюрпризный момент. Этот этап логопедического занятия проявлялся в неожиданных поворотах сюжетных линий, различных вариациях подсказок, а также в воспроизведении видеофрагментов мультипликационных проектов, которые выступали в роли ключевого звена развития сюжета.

5. Физкультминутка. Наполнение этого фрагмента логопедического занятия производится на усмотрение педагога. В интерактивных тренажерах к данному этапу подводят реплики основных действующих лиц.

6. Постановка корригируемого звука. Эта часть отражена во всех тренажерах, кроме тех, что нацелены на дифференциацию проблемных звуков. Задания этой части подразумевают изолированное произношение проблемных звуков совместно с мультипликационными героями интерактивных тренажеров.

7. Автоматизация корригируемого звука в слогах. Данный этап логопедического занятия представлен в виде упражнений, подразумевающих создание и воспроизведение открытых и закрытых слогов с участием корригируемых звуков. Интерактивность этих упражнений позволяет успешно отработать один из базовых навыков.

8. Автоматизация корригируемого звука в словах. Этот блок занятия включает в себя задания, позволяющие определить наличие корригируемого звука, найти его место в предлагаемых словах.

9. Автоматизация корригируемого звука в предложениях. Упражнения этого этапа подразумевают составление предложений, имеющих в своем составе слова с наличием отрабатываемого звука.

10. Дифференциация артикуляторных поз поставленных звуков. На данном этапе ребенку наглядно демонстрируется разница артикуляторных поз.

11. Дифференциация поставленных звуков в слогах и словах. Упражнения данной ступени нашли свое отражения в слоговых тропинках и словах-метаграммах.

12. Дифференциация поставленных звуков в чистого- 
ворках и словосочетаниях. Этот этап представлен в виде словосочетаний со стечением дифференцируемых звуков, а также в звучных чистоговорках, вызывающих особую заинтересованность.

13. Рефлексия. Данный этап отражается в вопросительных и оценивающих репликах мультипликационных героев интерактивных тренажеров.

Важным моментом применения тренажеров являлось привлечение внимания ребенка к общей занимательной теме, например, в процессе работы над постановкой и автоматизацией [c] дети работали с героями мультипликационного фильма «Фиксики» в течение ряда логопедических занятий. Такая возможность обеспечивалась разным объемом слайдов в тренажерах. Тренажеры на 60-80 слайдов применялись в течение 3-4 занятий; применение меньших по объему тренажеров (30-40 слайдов) ограничивалось рамками 1-2 занятий. Вместе с тем, к каждому тренажеру можно было обращаться неоднократно в качестве закрепления материала.

Во время работы с интерактивными тренажерами реализовывался принцип объективного оценивания работы ребенка с тренажерами, все результаты высвечивались на экране, как правило, с использованием мультипликационных героев или образов, что делало в глазах ребенка оценку результатов его деятельности более объективной и эмоционально окрашенной.

Основной формой проведения коррекционной работы выступили подгрупповые занятия. Подгруппы формировались с учетом результатов эксперимента и дружеских симпатий детей. Длительность занятий составляла 30-35 минут; всего было проведено 20 занятий. В индивидуальном порядке проводились занятия с теми детьми, которым требовалось закрепить усвоенный материал.
Как известно, по нормам СанПина использование компьютера на логопедических занятиях с дошкольниками не должно превышать 10 минут, учитывая это, разработанные конспекты подразумевали их частичное внедрение в цикл логопедических занятий, направленных на коррекцию проблемных групп звуков. Мы заменяли в традиционных логопедических конспектах на выбор один из этапов на тот, что был отражен в нашей разработке. Такой подход не позволял нарушить требования СанПина и в свою очередь повышал мотивацию к занятиям у дошкольников. Кроме того, разнообразил коррекционные занятия, связав их цикл единой сюжетной линией.

Таким образом, в ходе опытно-экспериментальной работы нами был разработан и апробирован комплекс логопедических занятий с применением интерактивных логопедических тренажеров, направленных на коррекцию звукопроизношения дошкольников с общим недоразвитием речи. Особенностями разработанных тренажеров являлись: открытость (возможность трансформации, доработки); обновляемость; многовариативность использования в образовательном процессе; интерактивность (взаимодействие с пользователем, обеспечивающее самостоятельные действия ребенка); инновационность (изменение характера взаимодействия между субъектами образовательного процесса). Апробация разработанного комплекса тренажеров позволила повысить эффективность работы по коррекции звукопроизношения дошкольников с общим недоразвитием речи. Контрольный эксперимент показал, что в результате коррекционных занятий с использованием логопедических тренажеров был повышен уровень сформированности звукопроизносительных навыков у дошкольников с ОНР, принявших участие в исследовании.

\section{ЛИТЕРАТУРА}

1. Архипова С.В. Информационная компетентность педагога-дефектолога / С.В. Архипова, А.С. Чаприна. - Текст : непосредственный // Гуманитарные науки и образование. -2019 . - Т. 10. - № 2. - С. 7-14.

2. Архипова С.В. Применение информационно-коммуникационных технологий субъектами сопровождения дошкольников с множественными нарушениями развития / С.В. Архипова, С.Ю. Шемырева. - Текст : непосредственный // Проблемы современного педагогического образования. Сер. : Педагогика и психология : Сборник научных трудов. - 2018.- Вып. 58. - Ч. 2. - С. $18-23$.

3. Гордиевских В.М. Технические средства обучения : учебное пособие / В.М. Гордиевских. - Москва : Гном и Д, 2000. - 129 с. - Текст : непосредственный.

4. К Коджаспирова Г.М. Технические средства обучения и методика их использования : учебное пособие / Г.М. Коджаспирова, К.В. Петров. - Москва : Академия, 2008. - 352 с. - ISBN: 978-5-7695-5037-9. - Текст : непосредственный.

5. Лаврентьева М.А. Развитие самостоятельности обучающихся с дизорфографией средствами компьютерных тренажеров / М.А. Лаврентьева, Е.Д. Балашкина - Текст : электронный // Проблемы современного педагогического образования. - 2019. - № 63. - Ч. 3. - С. 63-66. - URL : https://elibrary.ru/item. asp?id=38165877.

6. Михеева А.Н. Коррекционно-развивающие технологии с использованием компьютера в работе логопеда / А.Н. Михеева. - Текст : электронный // Логопедические технологии в условиях инклюзивного обучения детей с нарушением речи : материалы II Междунар. науч-практ. конф., 14-15 фев. 2013 г. / науч. ред. И.А. Филатова, А.В. Кубасов ; МГПУ. - М., 2013. - C. 55-60. - URL : http://elar.uspu.ru/handle/uspu/2230?mode=full. - Дата публикации : 22.10.2015. 
7. Репина 3.А. Компьютерные средства обучения: проблемы разработки и внедрения / Л.Р. Лизунова, З.А. Репина. - Текст : непосредственный // Вопросы гуманитарных наук. - 2004. - № 5. - С. 283-285.

8. Яковлева И.В. Возможности использования компьютерных технологий в обеспечении коррекционно-развивающего процесса в группах компенсирующей направленности (для детей с нарушениями речи Д00) / И.В. Яковлева. - Текст : электронный // Актуальные проблемы гуманитарных и естественных наук. - 2016. - № 1. - C. 101-103. - URL: https://noosphere.ru/pubs/437861. - Дата публикации : 26.05.2017.

( ) Минаева Наталья Геннадьевна (natmi27@уandex.ru), Ледакова Анна Владимировна (led1421@yandex.ru).

Журнал «Современная наука: актуальные проблемы теории и практики»

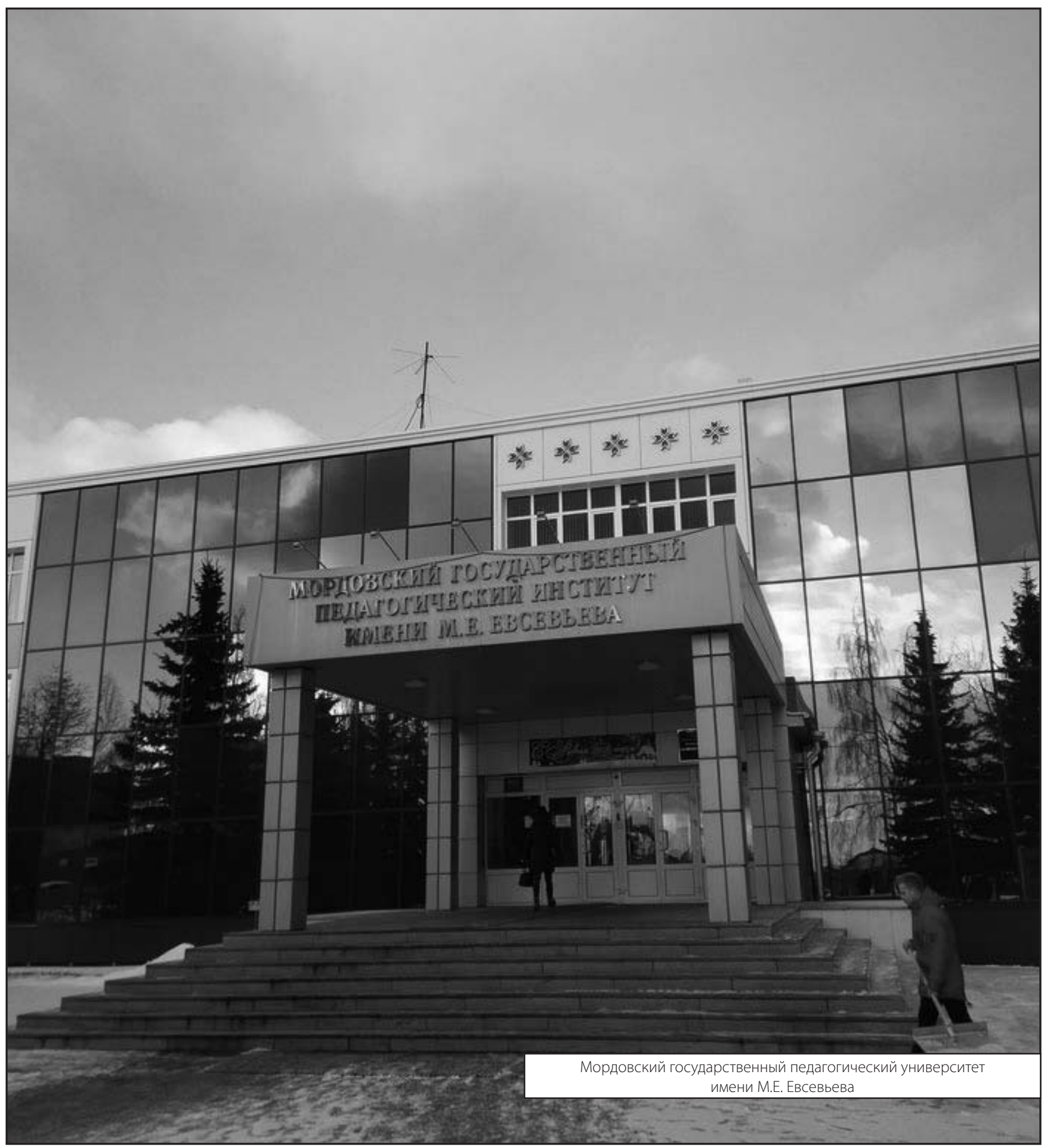

